6 Goldbaum LR, Orellano T, Dergal E. Mechanism of the toxic action of carbon monoxide. Ann Clin Lab Sci 1976;6: $372-6$

7 Thom SR. Carbon monoxide mediated brain lipid peroxidation in the rat. $₹$ Appl Physiol 1990;68:997-1003.

8 Penney DG, Helfman CC, Dunbar JC Jr, et al. Acute severe carbon monoxide exposure in the rat: effects of hyperglycaemia and hypoglycaemia on mortality, recovery and neurologic deficit. Can $\mathcal{F}$ Physiol Pharmacol 1991;69:1168-77.

9 Matsuoka M, Igisu H, Tanaka I, et al. Effects of hypo- and hyperglycaemia on brain energy metabolites in mice exposed to carbon monoxide. Toxicol Lett 1994;73:135-43.

10 Tomita M, Okuyama T, Shimosato K, et al. Effect of ethano on fatal carbon monoxide poisoning in awake mice. Toxico Lett 1990;50:151-7.

11 Denays R, Makhoul E, Dachy B, et al. Electroencephalographic mapping and ${ }^{99 \mathrm{~m}}$ Tc-HMPAO single-photon emission computed tomoraphy in carbon monoxide poisoning. Ann Emerg Med 1994;24:947-52.

12 Choi IS, Kim SK, Lee SS, et al. Evaluation of outcome of delayed neurological sequelae after carbon monoxide poisoning by technetium $-99 \mathrm{~m}$ hexamethylpropylene amine poisoning by technetium $-99 \mathrm{~m}$ hexamethylpropylene amine Eur Neurol 1995;35:137-42.

13 Turner $M$, Kemp PM. Isotope brain scanning with Turner M, Kemp PM. Isotope brain scanning with Tc-HMPAO: a predictor of outcome in carbon

14 Smith JS, Brandon S. Morbidity from acute carbon monoxSmith JS, Brandon S. Morbidity from acute carbon monox-
ide poisoning at three-year follow-up. BMF 1973;i:318-21 ide poisoning at three-year follow-up. BMF 1973;i:318-21.
Gorman DF, Clayton D, Gilligan JE, et al. A longitudinal 15 Gorman DF, Clayton D, Gilligan JE, et al. A longitudinal study of 100 consecutive admissions for carbon monoxide poisoning to the Royal Adelaide Hospital. Anaesth Intensive
Care 1992;20:311-16.

16 Turner $M$. The dangers of carbon monoxide poisoning. $N$ Engl f Med 1995;332:894.

17 Touger M, Gallagher EJ, Tyrell J. Relationship between venous and arterial carboxy-haemoglobin levels in patients with suspected carbon monoxide poisoning. Ann Emerg Med 1995;25:481-3.

18 Buckley RG, Aks SE, Eschom JL, et al. The pulse oximetry gap in carbon monoxide intoxication. Ann Emerg Med gap in carbon

19 Marius-Nunez AL. Myocardial infarction with normal coronary arteries after acute exposure to carbon monoxide. Chest 1990;97:491-4.

20 McMeekin JD, Finegan BA. Reversible myocardial dysfunction following carbon monoxide poisoning. Can $\mathcal{f}$ Cardiol 1987;3:118-21.
21 Levassuer L, Galliot-Guilley M, Richter F, et al. Effects of mode of inhalation of carbon monoxide and of normobaric mode of inhalation of carbon monoxide and of normobaric from the blod Hum Exp Toxicol 1996;15:898-903.

22 Raphael JC, Elkharrat D, Jars-Guincestre MC, et al. Trial of normobaric and hyperbaric oxygen for acute carbon monoxide intoxication. Lancet 1989;ii:414-19.

23 Norkool DM, Kirkpatrick JN. Treatment of acute carbon monoxide poisoning with hyperbaric oxygen: a review of 115 cases. Ann Emerg Med.1985;14:1168-71.

24 Thom SR. Antagonism of carbon monoxide-mediated brain lipid peroxidation by hyperbaric oxygen. Toxicol Appl Pharmacol 1990;105:340-4.

25 Thom SR. Functional inhibition of luekocyte $\beta_{2}$ integrins by hyperbaric oxygen in carbon monoxide-mediated brain injury in rats. Toxicol Appl Pharmacol 1993;123:248-56.

26 Tibbles PM, Perrotta PL. Treatment of carbon monoxide poisoning: a critical review of human outcome studies comparing normobaric oxygen with hyperbaric oxygen. Ann Emerg Med 1994;24:269-76.

27 Thom SR, Taber RL, Mendiguren II, et al. Delayed neuropsychologic sequelae after carbon monoxide poisoning: prevention by treatment with hyperbaric oxypoisoning: prevention by treatment with

28 Ducasse JI Celsis P, Marc-Vergnes JP. Non-comatose patients with acute carbon monoxide poisoning: hyperbaric patients with acute carbon monoxide poisoning: hyperbaric

29 Myers RAM, Snyder SK, Emhoff TA. Sub-acute sequelae of carbon monoxide poisoning. Ann Emerg Med 1985;14: carbon

30 Turner $\dot{M}$, Esaw M, Clark RJ. Carbon monoxide poisoning treated with hyperbaric oxygen: metabolic acidosis as a predictor of treatment requirements. $\mathcal{F}$ Accid Emerg Med 1999;16:96-8.

31 Tom T, Abedon S, Clark RI, et al. Neuroimaging characteristics in carbon monoxide toxicity. $\mathcal{F}$ Neuroimaging 1996;6: 161-6.

32 Pracyk JB, Stolp BW, Fife CE, et al. Brain computerised tomography after hyperbaric oxygen therapy for carbon monoxide poisoning. Undersea Hyperb Med 1995;22:1-7.

33 Horowitz AI Kaplan R Sarpel G Carbon monoxide toxicity: MR imaging in the brain. Radiology 1987;162: $787-8$.

34 Turner M, Clark RJ. Glioblastoma presenting as carbon monoxide poisoning. 7 Accid Emerg Med 1999;16:155-6.

35 Krenzelok EP, Roth R, Full R. Carbon monoxide .... the silent killer with an audible solution. Am 7 Emerg Med $1996 ; 14: 484-6$.

\title{
Carbon monoxide poisoning treated with hyperbaric oxygen: metabolic acidosis as a predictor of treatment requirements
}

Mark Turner, Michelle Esaw, Robin J Clark

Department of

Cardiology, Derriford Hospital, Plymouth, Devon PL6 8HD

M Turner

Royal Naval Hospital

Haslar, Gosport

$M$ Esaw

R J Clark

Correspondence to: Dr Turner, Specialist Registrar in Cardiology.

Accepted 4 June 1998
Abstract

A retrospective case note analysis was made of patients who received hyperbaric oxygen for carbon monoxide poisoning and were admitted to the Royal Naval Hospital Haslar between 1991 and 1995. Males predominated (38 $v 10)$ as did cases of deliberate self poisoning (31 $v$ 17). The most common presenting feature was unconsciousness, which is an indication for hyperbaric oxygen and therefore reflects referral patterns.

If patients had not recovered completely after one hyperbaric exposure further treatments were given. The initial hydrogen ion concentration of those requiring more than one treatment was significantly higher than those who recovered after the first treatment. The initial carboxyhaemoglobin $(\mathrm{COHb})$ concentra- tion showed only a trend to being higher in the multiple treatment group. Although metabolic acidosis is well recognised, its relationship to treatment requirements has not been shown previously. Initial COHb does not always correlate well with severity of poisoning which relates to the mechanism of toxicity of carbon monoxide: binding of carbon monoxide to the intracellular oxygen carrying proteins (for example cytochromes) rather than solely to haemoglobin. These findings are consistent with this mechanism and suggests that initial acidosis is a better predictor of treatment requirements and severity than initial COHb.

(F Accid Emerg Med 1999;16:96-98)

Keywords: carbon monoxide poisoning; hyperbaric oxygen treatment 


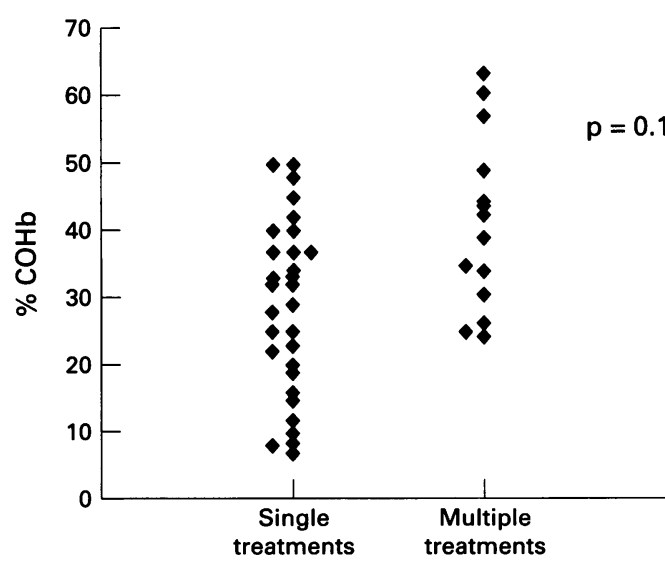

Figure 1 Initial $\mathrm{COHb}$ in the single and multiple treatment groups.

Carbon monoxide poisoning (CMP) is a leading cause of death from poisoning in the $\mathrm{UK}^{1}$ : in 1992 there were 1208 deaths in England and Wales. ${ }^{2}$ Treatment with hyperbaric oxygen is recommended in severe cases characterised by neurological and cardiovascular manifestations.

There is evidence, assessed by self administered questionnaire, that patients who never lose consciousness have a good outcome. ${ }^{3}$ Hyperbaric oxygen may be of value in preventing late sequelae ${ }^{4}$ (new neurological or cognitive manifestations presenting more than three days after poisoning) and has been used to treat symptoms many days after exposure. ${ }^{5}$ The possible reduction in late sequelae may be important because delayed morbidity may go unrecognised after CMP. ${ }^{6}$

Measurement of carboxyhaemoglobin $(\mathrm{COHb})$ concentration is indicated to confirm the diagnosis, but the percentage of $\mathrm{COHb}$ in the blood is not always a good indicator of severity. ${ }^{7}$ The main impact of the poisoning is on the intracellular oxygen carrying proteins rather than on the blood, ${ }^{8}$ therefore it is more logical to seek a marker of tissue poisoning. Poisoning of the cytochrome system leads to cellular dysfunction and metabolic acidosis which has previously been described in carbon monoxide poisoning, ${ }^{9}$ but its importance as a marker of severity has never been shown.

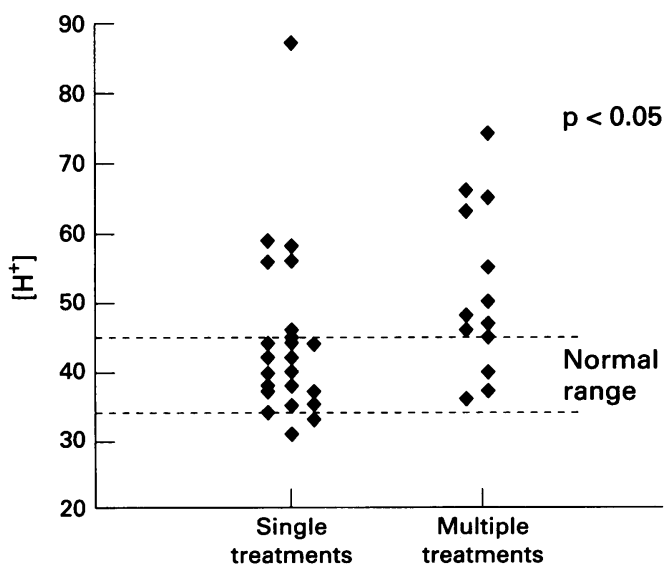

Figure 2 Initial $\left[\mathrm{H}^{+}\right]$in the single and multiple treatment groups.

\section{Methods}

A retrospective analysis of hospital notes was performed. All patients admitted to the Royal Naval Hospital Haslar after treatment with hyperbaric oxygen between 1991 and April 1995 were identified. Some patients given hyperbaric oxygen were returned to the referring hospital without being admitted to Haslar and are therefore not included.

Initial $\mathrm{COHb}$ and hydrogen ion concentration $\left(\left[\mathrm{H}^{+}\right]\right)$were ascertained from the casualty notes or laboratory reports from the referring hospital. Plasma salicylate concentrations were recorded when available. At the time of the study patients who had fully recovered after one hyperbaric treatment did not receive any further therapy. If the patient had made an incomplete recovery or if assessment could not be made, due to the continued need for respiratory support and sedation, a further hyperbaric treatment was undertaken. Subsequent treatments were given if the patient had responded to the previous treatment but still had not made a complete recovery. On this basis, the patients were separated into two groups: single and multiple treatments. The null hypotheses are that the multiple treatment group did not have higher $\mathrm{COHb}$ or $\left[\mathrm{H}^{+}\right]$at the time of presentation than the single treatment group. Non-parametric statistics were applied in the form of one tailed Kolmogorov-Smirnoff tests. $^{10}$

\section{Results}

Forty eight patients were identified: 14 received multiple treatments and 34 a single treatment. The majority $(n=31)$ of the patients were deliberate self poisonings (caused by running a hose from the exhaust pipe to the interior of the car). The next most common cause was incomplete combustion in a malfunctioning domestic heater $(n=12)$. The vast majority of patients had a history of unconsciousness at some time. Other symptoms included headache, nausea, and drowsiness.

Despite the severity of poisoning 36 patients made a good initial recovery, six improved, two had serious psychiatric illness, one died, and in two cases the outcome was not clearly recorded.

$\mathrm{COHb}$ and initial $\left[\mathrm{H}^{+}\right]$are shown in figs 1 and 2. Some data were missing. Of the 14 patients requiring multiple treatments, the $\left[\mathrm{H}^{+}\right]$was available in 13 ; salicylates were undetectable in 10, minimal in one, and unrecorded in three (only two of whom were acidaemic). The mean partial pressure of carbon dioxide was $4.62 \mathrm{kPa}$ in the multiple treatment group and $4.53 \mathrm{kPa}$ in the single treatment group (no significant difference). It was not always clear, from the notes from the referring hospital, whether patients were receiving assisted ventilation at the time of the initial arterial blood gas analysis. Of the 34 patients requiring one treatment the $\left[\mathrm{H}^{+}\right]$was available in 23 . There was a trend towards $\mathrm{COHb}$ concentrations being higher in the multiple treatment group $(p=0.1)$. The majority of patients in the single treatment group had a $\left[\mathrm{H}^{+}\right]$in the normal range compared with only $3 / 13$ in the multiple 
treatment group. The initial $\left[\mathrm{H}^{+}\right]$was significantly higher in the multiple treatment group $(p<0.05)$, thus rejecting this null hypothesis.

\section{Discussion}

The cause and manifestations of CMP in this group are consistent with previously-reported series from other hyperbaric centres. ${ }^{9}$ The key finding is the difference in $\left[\mathrm{H}^{+}\right]$at admission between the single and multiple treatment groups. This is consistent with the mechanism of toxicity of CMP.

Initial $\left[\mathrm{H}^{+}\right]$may be an index of severity of poisoning because of its effect on cellular metabolism due to binding of carbon monoxide to intracellular oxygen carrying proteins, for example cytochromes. Despite the small numbers, a significant association with acidaemia on admission and the need for multiple treatments was found and should be investigated further.

Previous studies have found that $\mathrm{COHb}$ does not correlate well with severity of poisoning. ${ }^{6}$ The reasons include: timing of measurement, rate of elimination, duration of exposure, and concentration of carbon monoxide in the inspired gas. In our patients there was a trend towards $\mathrm{COHb}$ being predictive of the need for multiple treatments but statistical significance was not reached.

The need for more than one treatment is only a surrogate measure of severity. The assessment of outcome of patients with CMP, particularly those due to deliberate poisoning, is difficult and may not necessarily be correlated with the severity of poisoning. Outcome may be confounded by premorbid state, cognitive reserve, and the response to treatment. It is therefore equally valid to use the amount of treatment required, so long as indications for repeat treatments are consistent and were not influenced by the initial $\left[\mathrm{H}^{+}\right]$. During the period of this study the initial $\left[\mathrm{H}^{+}\right]$was not one of the indications for repeat treatment. A predictor of the amount of treatment needed in itself may be helpful.
The management of CMP is based primarily on the clinical condition of the patient, however some recommend hyperbaric oxygen on the basis of a high $\mathrm{COHb}$ concentration at presentation. Acidaemia may give an additional measure of severity of poisoning and, in this study, correlated better with the need for multiple treatments than did $\mathrm{COHb}$. More specific measures of cellular dysfunction, such as lactate, should also be considered for further investigation. These data alone do not suggest that patients with an initial metabolic acidosis require multiple treatments, however patients with such an acidosis must be considered to have significant poisoning even if the $\mathrm{COHb}$ is low.

\section{Conclusion}

Initial assessment of the patient with CMP should include a full history and clinical examination, $\mathrm{COHb}$ concentration (confirming exposure), and arterial $\left[\mathrm{H}^{+}\right]$. Future studies of carbon monoxide poisoning should include data on initial $\left[\mathrm{H}^{+}\right]$.

We acknowledge Dr Roger Pethybridge, Institute of Naval Medicine for statistical advice.

1 Broome JR, Pearson RR, Skrine H. Carbon monoxide poisoning, forgotten not gone! Brf Hosp Med 1988;39:298305.

2 Office of Population Censuses and Surveys. Mortality statistics by cause England and Wales. London: HMSO, 1992. Series DH2 No 19.

3 Raphael JC, Elkharrat D, Jars-Guincestre MC, et al. Trial of normobaric and hyperbaric oxygen for acute carbon monoxide intoxication. Lancet 1989;ii:414-19.

4 Thom SR, Taber RL, Mendiguren II, et al. Delayed neuropsychologic sequelae after carbon monoxide neuropsychologic sequelae after carbon monoxide poisoning: prevention by treatment

5 Myers RAM, Snyder SK, Emhoff TA. Sub-acute sequelae of Myers RAM, Snyder SK, Emhoff TA. Sub-acute sequelae of
carbon monoxide poisoning. Ann Emerg Med 1985;14:

1163-7.

6 Smith JS, Brandon S. Morbidity from acute carbon monoxide poisoning at three-year follow-up. $B M \mathscr{F}$ 1973;i:318-21.

7 Norkool DM, Kirkpatrick JN. Treatment of acute carbon monoxide poisoning with hyperbaric oxygen: a review of 115 cases. Ann Emerg Med 1985;14:1168-71.

8 Goldbaum LR, Orellano T, Dergal E. Mechanism of the toxic action of carbon monoxide. Ann Clin Lab Sci 1976;6: $372-6$.

9 Gorman DF, Clayton D, Gilligan JE, et al. A longitudinal study of 100 consecutive admissions for carbon monoxide poisoning to the Royal Adelaide Hospital. Anaesth Intensive Care 1992;20:311-16.

10 Siegel S. Non-parametric statistics for the behavioural sciences. New York: McGraw-Hill, 1956.

\title{
British Hyperbaric Association carbon monoxide database, 1993-96
}

\author{
Martin R Hamilton-Farrell
}

Hyperbaric Unit, Whipps Cross Hospital, London E11 1NR

Correspondence to: Dr Hamilton-Farrell, Consultant Anaesthetist, Director of Hyperbaric Unit.
Abstract

Objectives-To study the referral pattern of patients, poisoned with carbon monoxide and subsequently transferred to British hyperbaric oxygen facilities, from April 1993 until March 1996 inclusive.

Methods-A standard dataset was used by hyperbaric facilities within the British Hyperbaric Association. The data on each patient were sent in confidence to the
Hyperbaric Unit at Whipps Cross Hospital for analysis. The epidemiology of poisoning and the population studied were analysed. Times of removal from exposure, referral to a hyperbaric facility, arrival at the hyperbaric facility, and start of treatment were recorded. Data on the outcome of the episode were documented in one of the contributing facilities. 